\title{
The naturally occurring $\alpha$-tocopherol stereoisomer RRR- $\alpha$-tocopherol is predominant in the human infant brain
}

\author{
Matthew J. Kuchan ${ }^{1 *}$, Søren K. Jensen ${ }^{2}$, Elizabeth J. Johnson ${ }^{3}$ and Jacqueline C. Lieblein-Boff ${ }^{1}$ \\ ${ }^{1}$ Research, Scientific and Medical Affairs, Abbott Nutrition, Columbus, OH 43219, USA \\ ${ }^{2}$ Department of Animal Sciences, Aarbus University, Blichers Allé 20, DK-8830 Tjele, Denmark \\ ${ }^{3}$ Tufts University, Boston, MA 02111, USA
}

(Submitted 14 October 2015 - Final revision received 19 March 2016 - Accepted 31 March 2016 - First published online 16 May 2016)

\section{Abstract}

$\alpha$-Tocopherol is the principal source of vitamin E, an essential nutrient that plays a crucial role in maintaining healthy brain function. Infant formula is routinely supplemented with synthetic $\alpha$-tocopherol, a racaemic mixture of eight stereoisomers with less bioactivity than the natural stereoisomer RRR- $\alpha$-tocopherol. $\alpha$-Tocopherol stereoisomer profiles have not been previously reported in the human brain. In the present study, we analysed total $\alpha$-tocopherol and $\alpha$-tocopherol stereoisomers in the frontal cortex (FC), hippocampus (HPC) and visual cortex (VC) of infants ( $n$ 36) who died of sudden infant death syndrome or other conditions. $R R R$ - $\alpha$-tocopherol was the predominant stereoisomer in all brain regions $(P<0.0001)$ and samples, despite a large intra-decedent range in total $\alpha$-tocopherol $(5-17 \mu \mathrm{g} / \mathrm{g})$. Mean $R R R-\alpha$-tocopherol concentrations in FC, HPC and VC were $10.5,6.8$ and $5.5 \mu \mathrm{g} / \mathrm{g}$, respectively. In contrast, mean levels of the synthetic stereoisomers were RRS, $1-1.5 ; R S R, 0.8-1 \cdot 0 ; R S S, 0 \cdot 7-0.9$; and $\Sigma 2 S 0 \cdot 2-0.3 \mu \mathrm{g} / \mathrm{g}$. Samples from all but two decedents contained measurable levels of the synthetic stereoisomers, but the intra-decedent variation was large. The ratio of $R R R$ :the sum of the synthetic $2 R$ stereoisomers (RRS $+R S R+R S S$ ) averaged $2.5,2.3$ and 2.4 in FC, HPC and VC, respectively, and ranged from 1 to at least $4 \cdot 7$, indicating that infant brain discriminates against synthetic $2 R$ stereoisomers in favour of $R R R$. These findings reveal that $R R R$ - $\alpha$-tocopherol is the predominant stereoisomer in infant brain. These data also indicate that the infant brain discriminates against the synthetic $2 R$ stereoisomers, but is unable to do so completely. On the basis of these findings, investigation into the impact of $\alpha$-tocopherol stereoisomers on neurodevelopment is warranted.

\section{Key words: RRR- $\boldsymbol{\alpha}$-tocopherol: Natural vitamin E: Brain: Infants}

Vitamin $\mathrm{E}$ is an essential nutrient consumed through foods including vegetable oils, nuts, dark green leafy vegetables and egg yolk ${ }^{(1)}$ and also through supplemented foods. Vitamin E is believed to be particularly important in the nervous system, as deficiency in humans, although rare, leads to neuromuscular abnormalities with ataxia and myopathy, and can be reversed by $\alpha$-tocopherol supplementation or consumption ${ }^{(2-4)}$. Vitamin E activity can be derived from four tocopherols $(\alpha, \beta, \gamma$ and $\delta)$ and their corresponding four tocotrienols $(\alpha, \beta, \gamma$ and $\delta$ ). However, $\alpha$-tocopherol is the most biologically active form of vitamin $\mathrm{E}^{(1)}$. $\alpha$-Tocopherol is widely accepted to play an important role in the protection of membrane-bound unsaturated fatty acids from oxidation through its potent lipid-soluble, chain-breaking antioxidant activity. In addition, it is thought to support diverse biological processes including regulation of enzymatic activity ${ }^{(5)}$, gene expression $^{(6)}$ and cell signalling ${ }^{(6,7)}$.

The three chiral $\mathrm{C}$ atoms in the structure of $\alpha$-tocopherol result in significant structural complexity. In nature, $\alpha$-tocopherol only exists as the $R R R$ stereoisomer $\left(2 R, 4^{\prime} R, 8^{\prime} R\right.$ - $\alpha$-tocopherol), commonly referred to as natural vitamin E. In contrast, synthetic $\alpha$-tocopherol (all-rac- $\alpha$-tocopherol) is a racaemic mixture of the eight possible stereoisomers. On the basis of these differences in stereochemistry, $R R R$ - $\alpha$-tocopherol has greater biological value than all-rac- $\alpha$-tocopherol. Extensive research has indicated that $R R R$ - $\alpha$-tocopherol has 1.36-2 times the biological value of all-rac$\alpha$-tocopherol ${ }^{(8,9)}$. Discrimination among stereoisomers is known to occur in the liver through the action of $\alpha$-tocopherol transfer protein $(\alpha \text {-TTP })^{(10)}$, which preferentially binds $2 R$ stereoisomers, resulting in degradation of the majority of $2 S$ stereoisomers in all-rac- $\alpha$-tocopherol ${ }^{(11)}$.

Rodent and pig peripheral tissue $\alpha$-tocopherol stereoisomer composition appears to reflect hepatic $\alpha$-tocopherol stereoisomer discrimination. The brain and other peripheral tissues of rats fed all-rac- $\alpha$-tocopherol contain dramatically higher levels of $2 R$ than of $2 S$ stereoisomers ${ }^{(12,13)}$. Consistent with enrichment of $2 R$ stereoisomers via hepatic discrimination, mice fed equal quantities of $\mathrm{d}_{3}$-RRR- $\alpha$-tocopherol and $\mathrm{d}_{6}$-all-rac- $\alpha$-tocopherol had a brain $\mathrm{d}_{3}: \mathrm{d}_{6}$ ratio of approximately $1 \cdot 8^{(14)}$. Weiser et al. ${ }^{(15)}$ directly tested individual $2 R$ stereoisomers in brain samples from $\alpha$-tocopherol-deprived rats repleted with all-rac- $\alpha$-tocopherol and

Abbreviations: FC, frontal cortex; HPC, hippocampus; VC, visual cortex; $\alpha$-TTP, $\alpha$-tocopherol transfer protein.

* Corresponding author: M. J. Kuchan, fax +1 614727 4537, email matthew.kuchan@abbott.com 
found no discrimination among $2 R$ stereoisomers. Piglets fed sow milk containing a $2: 1 \mathrm{~d}_{3}: \mathrm{d}_{6}$ ratio had a $2: 1$ ratio in plasma and 2.6 and 2.4 ratios in the brain after 14 and $21 \mathrm{~d}$ of nursing, respectively ${ }^{(16)}$. Although others have reported total $\alpha$-tocopherol concentrations in the adult and fetal human brain ${ }^{(17-19)}$, no information is available on the $\alpha$-tocopherol stereoisomer composition in the infant human brain.

As human infants are generally born with low levels of plasma $\alpha$-tocopherol, their vitamin E status is heavily dependent on the $\alpha$-tocopherol content and composition of human milk or infant formula. Infant formula is widely supplemented with all-rac- $\alpha$-tocopheryl-acetate in order to meet the vitamin $\mathrm{E}$ requirements of infants. Unlike breast-fed infants, formula-fed infants do not benefit from discrimination of $\alpha$-tocopherol stereoisomers in the maternal liver, possibly increasing the likelihood of synthetic stereoisomers reaching the infant brain. Expression of hepatic $\alpha$-TTP in neonatal mice is low at birth and increases to adult levels over the first $28 \mathrm{~d}$ of life ${ }^{(20)}$. However, it is not known whether the same developmental phenomenon occurs in human infants. Research in knockout mice has revealed that $\alpha$-tocopherol is essential for Purkinje cell integrity in the cerebellum through the action of $\alpha$-TTP ${ }^{(21)}$. As $\alpha$-TTP is known to discriminate between the $2 R$ stereoisomers of $\alpha$-tocopherol, we considered it important to determine the $\alpha$-tocopherol stereoisomer distribution in infant brain.

\section{Methods}

\section{Decedents and brain samples}

Voluntarily donated, frozen brain samples were obtained from the National Institute of Child Health and Human Development Brain and Tissue Bank for Developmental Disorders at the University of Maryland. Samples from thirty-three decedents were collected between 1995 and 2005 and between 2007 and 2008 from the remaining three decedents. Samples were voluntarily donated by the parents and were identified using a unique numerical identifier, which obscured the identity of the decedent. Identity-obscured autopsy reports were reviewed to confirm that decedents were otherwise healthy and did not suffer from brain abnormalities or other systemic pathologies. A total of seventy-nine samples were obtained from the frontal cortex (FC) ( $n$ 28), hippocampus (HPC) ( $n$ 25) and visual cortex (VC) ( $n$ 26), and it is noteworthy that these regions of the brain are associated with memory (HPC), executive function (FC) and vision (VC). Decedent details are provided in Table 1. Samples were available from all three regions of the brain from fourteen of the thirty-six decedents. Only two regions were analysed for fifteen decedents, and a single region for the remaining seven decedents. Tissues were stored frozen $\left(-70^{\circ} \mathrm{C}\right)$ until analysis for $\alpha$-tocopherol stereoisomers. Term and preterm decedents were combined as values for total $\alpha$-tocopherol and $\alpha$-tocopherol stereoisomer profile for the preterm infants fell within the term infant range.

\section{$\alpha$-Tocopherol analyses}

The concentrations of tocopherols including $\gamma$-tocopherol were determined by HPLC after saponification and extraction into heptane. The stereochemical composition of $\alpha$-tocopherol was
Table 1. Descriptive characteristics of decedents (Numbers and percentages; mean values and standard deviations; thirty-six infants)

\begin{tabular}{|c|c|}
\hline Characteristics & $n \%$ \\
\hline \multicolumn{2}{|l|}{ Birth } \\
\hline Term* & 30 \\
\hline Preterm* & 6 \\
\hline \multicolumn{2}{|l|}{ Age (d) } \\
\hline Mean & 131 \\
\hline SEM & $17 \cdot 6$ \\
\hline Median & 100 \\
\hline Range & $5-488$ \\
\hline \multicolumn{2}{|l|}{ Sex } \\
\hline Females & 1038 \\
\hline Males & 2672 \\
\hline \multicolumn{2}{|l|}{ Race } \\
\hline African-American & 1850 \\
\hline Caucasian & 1747 \\
\hline Hispanic & 13 \\
\hline \multicolumn{2}{|l|}{ Cause of death } \\
\hline Sudden infant death syndrome & 1747 \\
\hline Other & 1953 \\
\hline Asphyxia & 4 \\
\hline Asthma & 1 \\
\hline Bronchopneumonia & 4 \\
\hline Congenital heart defects and heart disease & 4 \\
\hline $\begin{array}{l}\text { Complications of prematurity, bronchopulmonary } \\
\text { dysplasia }\end{array}$ & 2 \\
\hline Dehydration & 1 \\
\hline Drowning & 1 \\
\hline Hyperthermia & 1 \\
\hline Idiopathic pulmonary haemorrhage & 1 \\
\hline \multicolumn{2}{|l|}{ Postmortem interval $(\mathrm{h})$} \\
\hline Mean & 18 \\
\hline SEM & $1 \cdot 1$ \\
\hline Median & 19 \\
\hline Range & $2-28$ \\
\hline Postmortem interval $v$. total a-tocopherol $(P)$ & \\
\hline $\mathrm{FC}$ & 0.96 \\
\hline HPC & $0 \cdot 10$ \\
\hline VC & 0.55 \\
\hline Postmortem interval v. RRR-a-tocopherol $(P)$ & \\
\hline FC & 0.95 \\
\hline $\mathrm{HPC}$ & 0.48 \\
\hline VC & 0.96 \\
\hline
\end{tabular}

FC, frontal cortex; HPC, hippocampus; VC, visual cortex.

* Term, $\geq 37$ weeks of gestation at birth, and preterm, $<37$ weeks of gestation birth.

determined after methylation of $\alpha$-tocopherol stereoisomers into their corresponding methyl ethers and subsequent separation by chiral HPLC ${ }^{(22)}$. This method separates the eight stereoisomers of $\alpha$-tocopherol into five peaks: peak 1 contains the four $2 S$ stereoisomers (SSS/SSR/SRS/SRR), peak 2 contains RSS- $\alpha$ tocopherol, peak 3 contains $R R S$ - $\alpha$-tocopherol, peak 4 contains $R R R$ - $\alpha$-tocopherol and peak 5 contains RSR- $\alpha$-tocopherol. Results are reported as the ratio of the observed stereoisomer among five peaks and the concentration determined by calculation of each stereoisomer concentration from total $\alpha$-tocopherol. Recovery of total $\alpha$-tocopherol was $96 \%$ with a CV (\%) of $2 \cdot 7$, whereas recovery of the individual stereoisomers varied from $95 \cdot 3$ to $100 \cdot 8 \%$ with CV (\%) varying from 1.2 to $7 \cdot 9$. Data were expressed per wet weight of tissue.

\section{Statistical analysis}

To detect significant main effects and interactions between main factors, data were analysed with one-way 
(brain region; stereoisomer) ANOVA using GraphPad Prism version 5.04 for Windows (GraphPad Software, www. graphpad.com). When appropriate, differences between treatment means were evaluated by Tukey's multiple comparison test in GraphPad Prism. Means that differed significantly following a multiple comparison test were denoted using unique letter subscripts $(P<0.05)$. To determine significant correlations between nutrient concentrations and age or other nutrients, data were analysed using Pearson's correlation procedures of GraphPad Prism. All data are expressed as treatment means with their standard errors.

\section{Results}

\section{Total $\alpha$-tocopherol levels}

Mean total $\alpha$-tocopherol concentrations were not different across the three brain regions studied (Fig. 1). All samples analysed contained detectable concentrations of $\alpha$-tocopherol, and inter-decedent variation was large with values ranging from $<5$ to approximately $17 \mu \mathrm{g} \alpha$-tocopherol/g of tissue. Total $\alpha$-tocopherol concentration positively correlated with age in each of the three brain regions tested (FC, $r^{2} 0.31, P<0.01$; HPC, $r^{2} 0.36, P<0.01$; FC, $\left.r^{2} 0.62, P<0 \cdot 001\right)$. Intra-decedent variation in total $\alpha$-tocopherol concentrations by brain region is shown for the fourteen decedents who provided samples for each region (online Supplementary Table S1). $\boldsymbol{\gamma}$-Tocopherol was undetectable in the majority of samples (FC, twenty; HPC, fourteen; VC, twenty-one). Mean $\gamma$-tocopherol for samples with detectable levels was 0.30 (SEM 0.06) $\mu \mathrm{g} \quad \gamma$-tocopherol/g tissue ( $n$ 8), 0.36 (SEM 0.06) $\mu \mathrm{g}$ $\gamma$-tocopherol/g tissue $(n$ 11) and 0.33 (SEM 0.04) $\mu$ g $\gamma$-tocopherol $/ g$ tissue ( $n$ ) $)$ in FC, HPC and VC, respectively. Average ratios of $\alpha$-tocopherol: $\gamma$-tocopherol were 39, 33 and 25 in FC, HPC and VC, respectively. Neither total $\alpha$-tocopherol nor $R R R$ - $\alpha$-tocopherol (Table 1) was correlated with postmortem interval.

\section{$\alpha$-Tocopherol stereoisomers}

Mean concentrations of $R R R$ - $\alpha$-tocopherol were significantly higher than those of each of the synthetic $\alpha$-tocopherol

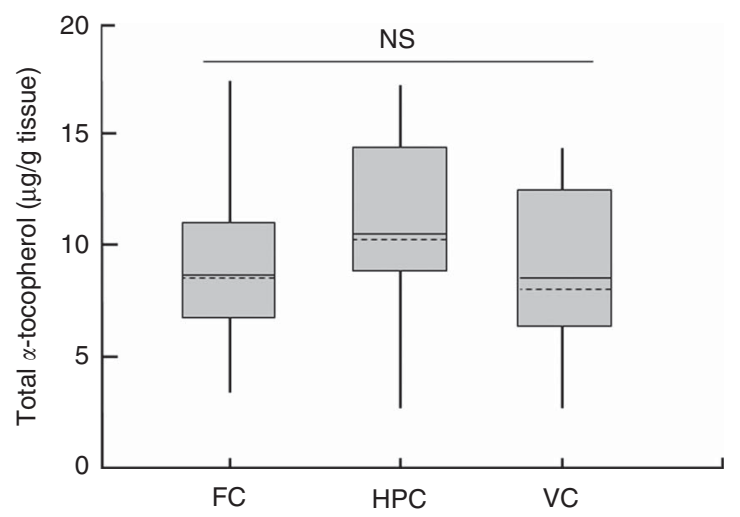

Fig. 1. Total $a$-tocopherol concentrations in the frontal cortex (FC), hippocampus (HPC) and visual cortex (VC). Data are from thirty-six decedents with twenty-eight FC samples, twenty-five HPC samples and twenty-six VC samples. $\square$, 25th and 75th percentiles; —-, mean; -----, median; |, minimum and maximum values. stereoisomers in each of the brain regions tested (Fig. 2(a-c)). Although $R R R$ - $\alpha$-tocopherol concentration positively correlated with age in each brain region studied (FC, $r^{2} 0 \cdot 22, P<0 \cdot 05$; HPC, $r^{2} 0.20, P<0.05$; VC, $\left.r^{2} 0.61, P<0.0001\right)$, individual synthetic stereoisomers did not. On average, across the brain regions, $R R R$ - $\alpha$-tocopherol accounted for $66 \%(P<0.0001$, compared with other stereoisomers) of total $\alpha$-tocopherol, whereas none of the synthetic stereoisomers exceeded $14 \%$. $R R R$ accounted for as much as $100 \%$ of total $\alpha$-tocopherol in two decedents. The minimum percentage of total $\alpha$-tocopherol found as $R R R$ was $58 \%$. More than half of the decedents had at least $30 \%$ of total $\alpha$-tocopherol as synthetic stereoisomers. Nonetheless, RRR- $\alpha$-tocopherol was the most common stereoisomer in all samples and individuals on a per cent basis. In order to provide insight into whether the stereoisomer profile was consistent for different brain regions within individual decedents, the stereoisomer profile is presented by brain region for the fourteen decedents who provided samples for all three regions (online Supplementary Table S1).

\section{$\alpha$-Tocopherol stereoisomer ratios}

The average ratio of the $R R R$ stereoisomer:the sum of synthetic $2 R$ stereoisomers was $>2$ (Fig. 3) with a range from a minimum of approximately 1 to a maximum of $6 \cdot 1,4.7$ and 4.9 for FC, HPC and VC, respectively; two samples, one from HPC and one from $\mathrm{VC}$, from different decedents, did not contribute ratios as the samples contained $100 \% R R R$.

\section{Discussion}

Although others have previously reported the concentration of total $\alpha$-tocopherol in human adult and fetal brain ${ }^{(17-19)}$, we believe we are the first to report the $\alpha$-tocopherol stereoisomer profile in the human infant brain. Our data reveal that $R R R$ - $\alpha$-tocopherol was the predominant stereoisomer of $\alpha$-tocopherol in each of the three regions of the infant brain studied. In fact, $R R R$ - $\alpha$-tocopherol was the predominant stereoisomer in each sample tested, despite high inter-decedent variation in $\alpha$-tocopherol. We found that the stereoisomer patterns were relatively consistent across the three brain regions in decedents with samples available for each region. The degree of discrimination in favour of $R R R$ - $\alpha$-tocopherol is striking as most infant formulae were supplemented with all-rac- $\alpha$-tocopherol. The extent of exposure of the decedents to all-rac- $\alpha$-tocopherol is emphasised by the finding that the brain samples of only one decedent was devoid of synthetic stereoisomers. That both total $\alpha$-tocopherol and $R R R$ $\alpha$-tocopherol were positively correlated with age in each brain region might provide further evidence of the importance of $\alpha$-tocopherol stereoisomer discrimination.

We believe the $\alpha$-tocopherol stereoisomer profile may be of particular importance to infants. First, vitamin E is an essential nutrient that plays an important role in neural function and development. Second, vitamin E requirements of formula-fed infants are routinely met using the less biologically active, 
(A)

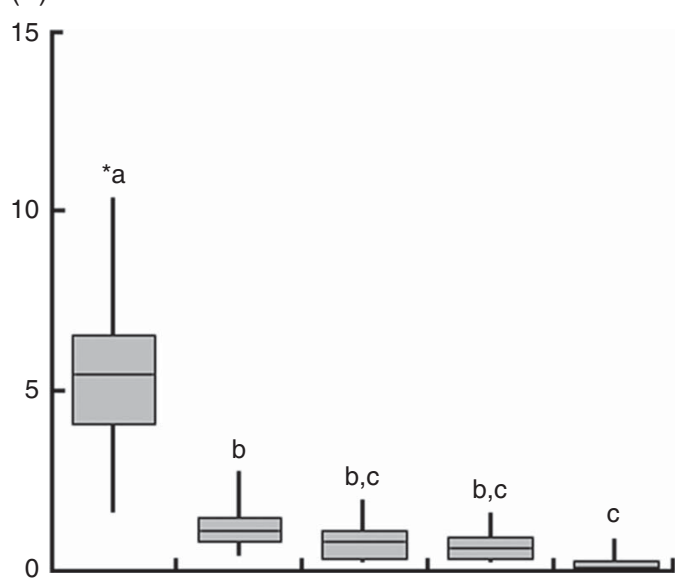

(B)

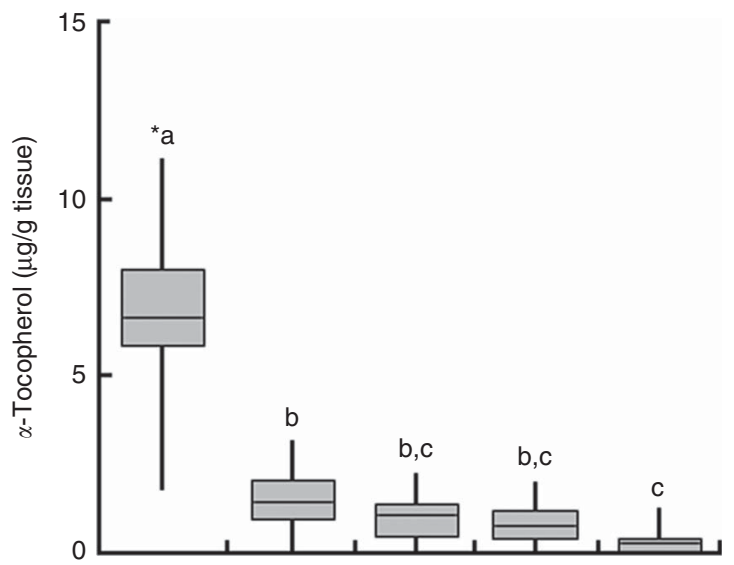

(C)

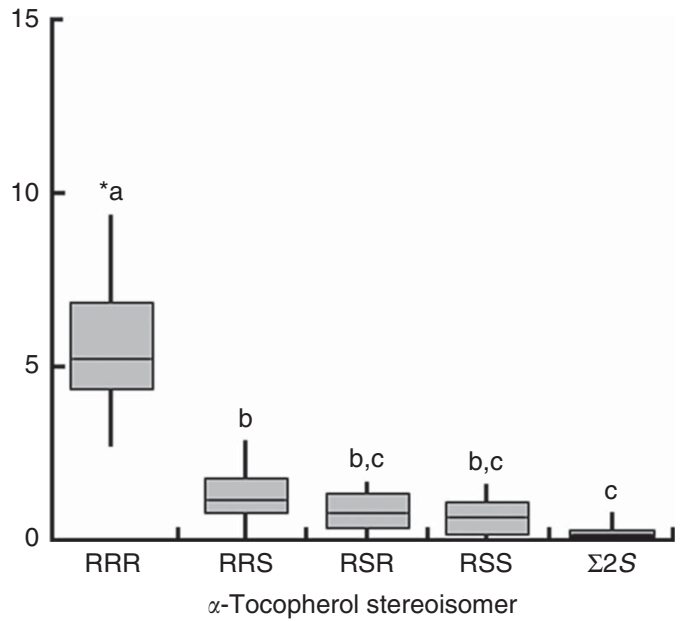

Fig. 2. $a$-Tocopherol stereoisomer profile in the frontal cortex (FC) (A), hippocampus (HPC) (B) and visual cortex (VC) (C) of the human infant brain. Data are from thirty-six decedents with twenty-eight FC samples, twenty-five HPC samples and twenty-six VC samples. The median values are not shown as they were very similar to the mean values. $\Sigma 2 S$ stereoisomers include SRR, SSR, SRS and SSS. a,b,c Stereoisomers with unlike superscript letters were significantly different: ${ }^{a} P<0.0001$; b,c $P<0.05$. * Different from other values for brain region $(P<0.0001)$. $\square, 25$ th and 75 th percentile values, __ , mean; |, maximum and minimum
values.

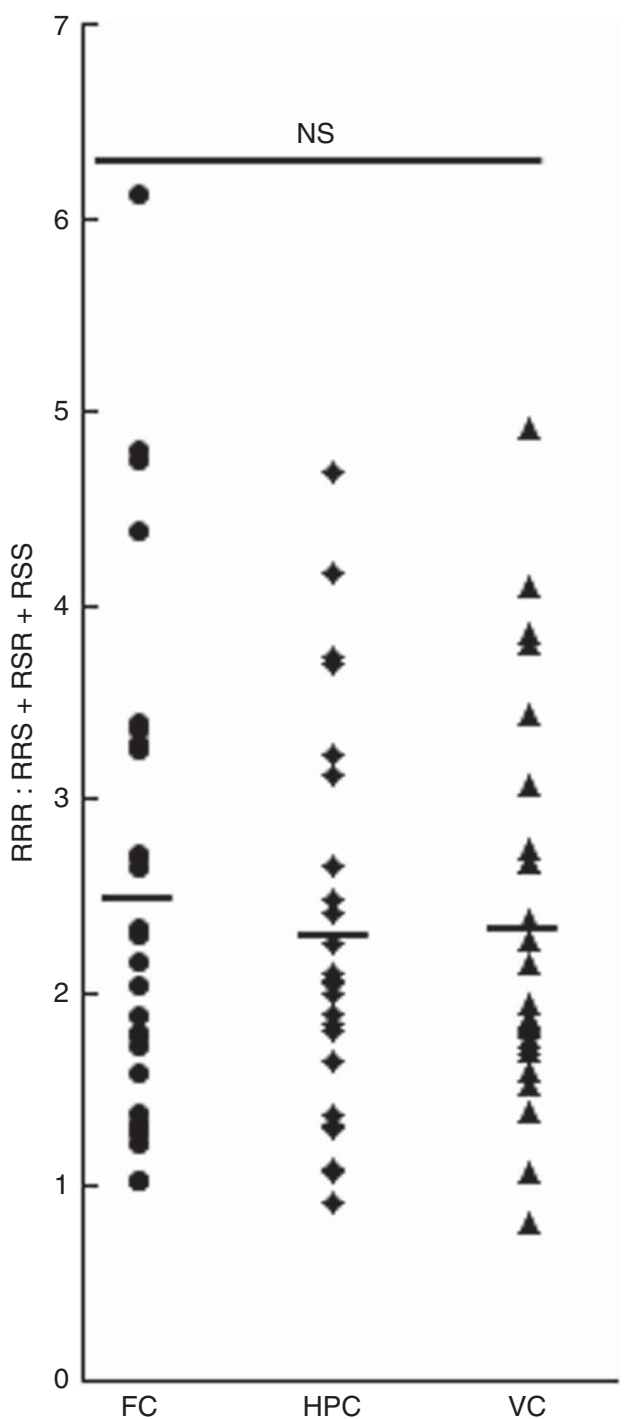

Fig. 3. The ratio of RRR- $a$-tocopherol:sum of RRS- $a$-tocopherol, RSR- $a$-tocopherol and RSS- $\alpha$-tocopherol stereoisomers in infant decedent samples from the frontal cortex (FC), hippocampus (HPC) and visual cortex (VC). Scatter plot of all values by brain region; horizontal bar indicates mean value.

synthetic source of vitamin E - all-rac- $\alpha$-tocopherol. Third, the state of development of the hepatic stereoisomer selection mechanism in infants has not been established.

Total $\alpha$-tocopherol concentrations reported here are lower than, but in line with, those previously reported for autopsied adult human brain ${ }^{(17-19)}$ and very similar to those for rat ${ }^{(15)}$ and piglet $^{(16)}$ brain. Although we cannot rule out the potential that tissue degradation before sample preservation could introduce artifact, no relationship was found between total $\alpha$-tocopherol concentration and time until tissue freezing. We believe that the slow turnover rate of $\alpha$-tocopherol in the brain ${ }^{(16,23,24)}$ may have reduced the potential for preservation artifact.

We found that all individuals tested had very low levels of $2 S$ stereoisomers and corresponding high levels of the $2 R$ stereoisomers of $\alpha$-tocopherol. This observation is largely consistent with previous animal research, revealing that rodent 
and piglet brains preferentially contain the $2 R$ stereoisomers of all-rac- $\alpha$-tocopherol ${ }^{(13,15,16)}$. Discrimination against $2 S$ stereoisomers is believed to occur in the liver. Hepatic $\alpha$-TTP-mediated discrimination in the infant and mother likely explains the low concentrations of $\gamma$-tocopherol we found in the infant brain samples. Despite high levels of $\gamma$-tocopherol in the American diet, breast milk generally has a 5:1 ratio of $\alpha$-tocopherol: $\gamma$-tocopherol. In addition, some infant formulae contain relatively high levels of $\gamma$-tocopherol, indicating that the infant liver also discriminates against $\gamma$-tocopherol in favour of $\alpha$-tocopherol ${ }^{(25)}$.

Previous research in animals does not provide definitive insight into whether there is discrimination between the $2 R$ stereoisomers in the brain. The single study published to date that directly quantified $2 R \alpha$-tocopherol stereoisomers in the brain revealed no selection among $2 R$ stereoisomers in $\alpha$-tocopherol-deficient rats repleted with all-rac- $\alpha$-tocopherol ${ }^{(15)}$. Our data, however, are consistent with preferential discrimination for $R R R$ - $\alpha$-tocopherol in the human infant brain. Extensive research in human adults and corroborative evidence in infants indicate that plasma from individuals consuming all-rac- $\alpha$-tocopherol has roughly equal concentrations of the $2 R$ stereoisomers ${ }^{(8,9,26)}$. Equal concentrations of $2 R$ stereoisomers result in a ratio of $R R R$ - $\alpha$-tocopherol:the sum of $R R S$ - $\alpha$-tocopherol, $R S R$ - $\alpha$-tocopherol and $R S S$ - $\alpha$-tocopherol of approximately $0 \cdot 33^{(8,26,27)}$. Therefore, if there was no stereoisomer discrimination in the infant brain, the minimum $R R R:(R R S+R S R+R S S)$ would be approximately $0.33^{(15)}$. It is highly likely that some of the decedents studied received predominantly all-rac- $\alpha$-tocopherol; however, the minimum ratio we observed was 0.7 with median brain values of 1.8 or higher in each brain region studied. These observations are consistent with significant selection among the $2 R$ stereoisomers in favour of $R R R-\alpha$-tocopherol.

Potential over-representation of breast-fed infants in the study cohort does not explain our observations. Consistent with observations in sow milk ${ }^{(16)}$, unpublished observations from our group (M Kuchan) suggest that breast milk from North American women contains a significant amount of synthetic $2 R \alpha$-tocopherol stereoisomers. This observation is based on 300 samples from more than 200 women and likely reflects the use of synthetic $\alpha$-tocopherol in maternal supplements. In addition, the results of this study indicate that both total and $R R R$ - $\alpha$-tocopherol increased with age during the 1st year, despite the rapid increase in brain volume known to occur over this period. We believe this diminishes the likelihood of possible confounding effects of maternal liver-placenta-infant liver tandem selection before birth. Enhanced discrimination between stereoisomers in the infant liver compared with that known to occur in the adult liver is inconsistent with published results in the human infant ${ }^{(25)}$. For these reasons, we believe that these data are best explained by a combination of discrimination for $R R R$ - $\alpha$-tocopherol in the infant brain and the source of $\alpha$-tocopherol consumed in the diet.

The predominance of $R R R$ - $\alpha$-tocopherol in the infant brain reported here might be explained by the presence of $\alpha$-TTP and tocopherol-associated protein (TAP) in the human brain. Extra-hepatic stereoisomer-specific discrimination has been previously demonstrated in the human fetus/fetal-placental unit ${ }^{(28,29)}$ and is believed to be at least partially explained by placental expression of $\alpha$-TTP ${ }^{(30)}$. The human cerebellum expresses $\alpha$-TTP ${ }^{(31)}$, and multiple regions of the human brain express relatively high levels of TAP ${ }^{(32)}$. TAP has a high degree of bindingsite sequence homology to $\alpha$-TTP, and similar to $\alpha$-TTP is known to possess differential affinity for tocopherol structural isomers ${ }^{(33)}$. These observations suggest that TAP may be capable of discrimination among $\alpha$-tocopherol stereoisomers.

In conclusion, these first-of-kind data reveal a clear, preferential accumulation of the naturally occurring stereoisomer $R R R$ - $\alpha$-tocopherol in the human infant brain. This is a surprising observation given the extensive exposure of the decedents to all-rac- $\alpha$-tocopherol. Our data are consistent with discrimination among the $2 R$ stereoisomers of all-rac- $\alpha$-tocopherol in favour of $R R R$ - $\alpha$-tocopherol. We believe this finding raises important questions, as biological discrimination often reflects biological importance. Emerging evidence suggests that $R R R$ - $\alpha$-tocopherol and all-rac- $\alpha$-tocopherol may have differential cellular effects mediated through gene expression ${ }^{(34)}$. It is not known whether there is an advantage of increased $R R R$ - $\alpha$-tocopherol, or if accumulation of synthetic stereoisomers is unfavourable for brain development. However, as vitamin $\mathrm{E}$ is essential for the integrity of cerebellar Purkinje neurons ${ }^{(21,35,36)}$ through the action of $\alpha$-TTP, a stereo-selective protein, we believe this is an important question for future research.

\section{Acknowledgements}

The authors express their deep appreciation to the National Institute of Child Health and Human Development Brain and Tissue Bank and parents for donating the extremely valuable samples tested in this study. Elsebeth Lyng Pedersen is greatly acknowledged for conducting the tocopherol analyses and Chron-si Lai for technical consultation.

This work was supported by Abbott Nutrition. E. J. J. was also supported by the United States Department of Agriculture 58-1950-1-014.

M. J. K.: conceived, designed, interpreted, drafted and critically reviewed the work. S. K. J.: analysis and critical review of the work. E. J. J.: acquisition of samples and critical review of the work. J. C. L.-B.: drafted the manuscript and critically reviewed the work. All the authors are accountable for the results.

None of the authors has any conflicts of interest to declare.

\section{Supplementary material}

For supplementary material/s referred to in this article, please visit http://dx.doi.org/doi:10.1017/S0007114516001719

\section{References}

1. Food and Nutrition Board \& Institute of Medicine (2000) Dietary Reference Intakes for Vitamin C, Vitamin E, Selenium, and Carotenoids. Washington, DC: National Academies Press.

2. Sokol RJ, Guggenheim M, Iannaccone ST, et al. (1985) Improved neurologic function after long-term correction of vitamin $\mathrm{E}$ deficiency in children with chronic cholestasis. $N$ Engl J Med 313, 1580-1586. 
3. Niki E \& Traber MG (2012) A history of vitamin E. Ann Nutr Metab 61, 207-212.

4. Traber MG, Sokol RJ, Ringel SP, et al. (1987) Lack of tocopherol in peripheral nerves of vitamin E-deficient patients with peripheral neuropathy. $N$ Engl J Med 317, 262-265.

5. Mahoney CW \& Azzi A (1998) Vitamin E inhibits protein kinase C activity. Biochem Biophys Res Commun 154, 694-697.

6. Azzi A, Gysin R, Kempna P, et al. (2004) Vitamin E mediates cell signaling and regulation of gene expression. Ann $N Y$ Acad Sci 1031, 86-95.

7. Azzi A (2007) Molecular mechanism of alpha-tocopherol action. Free Radic Biol Med 43, 16-21.

8. Brigelius-Flohe R \& Traber MG (1999) Vitamin E: function and metabolism. FASEB J 13, 1145-1155.

9. Traber MG (2007) Vitamin E regulatory mechanisms. Ann Rev Nutr 27, 347-362.

10. Ferslew KE, Acuff RV, Daigneault EA, et al. (1993) Pharmacokinetics and bioavailability of the $R R R$ and all racemic stereoisomers of alpha-tocopherol in humans after single oral administration. J Clin Pharmacol 33, 84-88.

11. Traber MG, Burton GW, Ingold KU, et al. (1990) RRR- and $S R R$-alpha-tocopherols are secreted without discrimination in human chylomicrons, but $R R R$-alpha-tocopherol is preferentially secreted in very low density lipoproteins. J Lipid Res 31, 675-685.

12. Ueda T, Ichikawa H \& Igarashi O (1993) Determination of a-tocopherol stereoisomers in biological specimens using chiral phase high-performance liquid chromatography. J Nutr Sci Vitaminol (Tokyo) 39, 207-219.

13. Nitta-Kiyose C, Hayashi K, Tadahiko U, et al. (1994) Distribution of a-Toc Stereoisomers in rats. Biosci Biotechnol Biochem 58, 2000-2003.

14. Leonard SW, Terasawa Y, Farese RV Jr, et al. (2002) Incorporation of deuterated RRR- or all-rac-alpha-tocopherol in plasma and tissues of alpha-tocopherol transfer protein - null mice. Am J Clin Nutr 75, 555-560.

15. Weiser H, Riss G \& Kormann AW (1996) Biodiscrimination of the eight alpha-tocopherol stereoisomers results in preferential accumulation of the four $2 \mathrm{R}$ forms in tissues and plasma of rats. J Nutr 126, 2539-2549.

16. Lauridsen C, Engel H, Jensen SK, et al. (2002) Lactating sows and suckling piglets preferentially incorporate $R R R$ - over all-rac-a-tocopherol into milk, plasma and tissues. J Nutr 132, 1258-1264.

17. Johnson EJ, Vishwanathan R, Johnson MA, et al. (2013) Relationship between serum and brain carotenoids, $\alpha$-tocopherol, and retinol concentrations and cognitive performance in the oldest old from the Georgia Centenarian Study. I Aging Res 2013, 951786

18. Craft NE, Haitema TB, Garnett KM, et al. (2004) Carotenoid, tocopherol, and retinol concentrations in elderly human brain. J Nutr Health Aging 8, 156-162.

19. Metcalfe T, Bowen DM \& Muller DPR (1989) Vitamin E concentrations in human brain of patients with Alzheimer's disease, fetuses with down's syndrome, centenarians, and controls. Neurochem Res 14, 1209-1212.
20. Kim HS, Arai H, Arita M, et al. (1996) Age-related changes of a-tocopherol transfer protein expression in rat liver. J Nutr Sci Vitaminol (Tokyo) 42, 11-18.

21. Ulatowski L, Parker R, Warrier G, et al. (2014) Vitamin E is essential for purkinje neuron integrity. Neurosci 260, 120-129.

22. Jensen SK, Norgaard JV \& Lauridsen C (2006) Bioavailability of alpha-tocopherol stereoisomers in rats depends on dietary doses of all-rac- or RRR-alpha-tocopheryl acetate. $\mathrm{Br} \mathrm{J} \mathrm{Nutr}$ 95, 477-487.

23. Vatassery GT, Angerhofer CK, Knox CA, et al. (1984) Concentrations of vitamin $\mathrm{E}$ in various neuroanatomical regions and subcellular fractions, and the uptake of vitamin $\mathrm{E}$ by specific areas, of rat brain. Biochim Biophys Acta $\mathbf{7 9 2}$, 118-122.

24. Vatassery GT, Angerhofer CK \& Paterson FJ (1984) Vitamin E concentrations in the brains and some selected peripheral tissues of selenium-deficient and vitamin E-deficient mice. J Neurochem 42, 554-558.

25. Stone WL, LeClair I, Ponder T, et al. (2003) Infants discriminate between natural and synthetic vitamin E. $A m J$ Clin Nutr 77, 899-906.

26. Kiyose C, Muramatsu R, Kameyama Y, et al. (1997) Biodiscrimination of a-tocopherol stereoisomers in humans after oral administration. Am J Clin Nutr 65, 785-789.

27. Traber MG, Elsnerb A \& Brigelius-Floheèb R (1998) Synthetic as compared with natural vitamin $\mathrm{E}$ is preferentially excreted as a-CEHC in human urine: studies using deuterated a-tocopheryl acetates. FEBS Lett 437, 145-148.

28. Acuff RV, Dunworth RG, Webb LW, et al. (1998) Transport of deuterium-labeled tocopherols during pregnancy. Am J Clin Nutr 67, 459-464.

29. Schenker S, Yang Y, Perez A, et al. (1998) Antioxidant transport by the human placenta. Clin Nutr 17, 159-167.

30. Gordon MJ, Campbell FM \& Dutta-Roy AK (1996) a-Tocopherol-binding protein in the cytosol of the human placenta. Biochem Soc Trans 24, 2025.

31. Copp RP, Wisniewski T, Hentati F, et al. (1999) Localization of a-tocopherol transfer protein in the brains of patients with ataxia with vitamin E deficiency and other oxidative stress related neurodegenerative disorders. Brain Res 822, 80-87.

32. Zimmer S, Stocker A, Sarbolouki MN, et al. (2000) A novel human tocopherol-associated protein: cloning, in vitro expression, and characterization. J Biol Chem 275 , 25672-25680.

33. Panagabko C, Morley S, Hernandez M, et al. (2003) Ligand specificity in the CRAL-TRIO protein family. Biochemistry $\mathbf{4 2}$, 6467-6474.

34. Han SN, Pang E, Zingg JM, et al. (2010) Differential effects of natural and synthetic vitamin $\mathrm{E}$ on gene transcription in murine T lymphocytes. Arch Biochem Biophys 495, 49-55.

35. Ulatowski LM \& Manor D (2015) Vitamin E and neurodegeneration. Neurobiol Dis 84, 78-83.

36. Hosomi A, Goto K, Kondo H, et al. (1998) Localization of a-tocopherol transfer protein in rat brain. Neurosci Lett 256, 159-162. 